Regarding the AAFP's call for partial incentives, Epperly said he was "greatly concerned about the capacity for many eligible providers, especially those in small and medium practices, to achieve all of the required criteria by 2011 and 2012." He added that CMS could miss a huge opportunity with its "all-ornothing" approach. Epperly said the AAFP did not want to discourage practices that couldn't achieve $100 \%$ of the requirements "from using, improving or implementing EHRs because they will receive no incentive for anything less."

The Academy had no issues with CMS' meaningful use goals but expressed concern about the proposed administrative burdens that would be placed on physicians to report the measures. "We strongly believe that efforts and resources in the practice need to be focused on the transformation of the practice and achieving high-quality care-not on tracking denominators for process measures," said Epperly.

In terms of team-based care, Epperly asked for revised wording that wouldn't require a physician to actually perform a task, but rather would make the physician responsible for ensuring completion of the work. This change "is critical to patient-centered care via a team-based approach to care," he said.

The Academy also spelled out its recommendations for changes in the proposed rule related to goals for meaningful use suggested by CMS, going so far as to ask the government to strike or delay some measures that either were duplicative or overly burdensome for physicians.

For example, the proposed rule has an objective on computerized provider order entry, or CPOE, that would require computerized entry for at least $80 \%$ of orders. "We believe that the administrative burden to report on the CPOE measure is excessive to the point of being unachievable for most eligible providers," said Epperly. He noted that most physicians would have to perform double-data entry because many labs, hospitals and diagnostic imaging centers do not accept standard electronic orders. "Based on the current state of adoption of CPOE in the ambulatory environment

...we recommend that the CPOE measure be removed until electronic orders are routinely transmittable," he said.

The AAFP also took issue with a measure requiring that at least $75 \%$ of prescriptions be transmitted electronically. Epperly pointed out that many physicians with e-prescribing capabilities don't use the technology because of pharmacy or patient resistance. In fact, only about $16 \%$ of prescriptions are sent electronically; therefore, the $75 \%$ threshold is likely unachievable by the majority of physicians "because of conditions not under their control," said Epperly. The Academy rec- ommended that the e-prescribing measure be reported with an absolute count of e-prescribed medications rather than a percentage of total prescriptions. Epperly also suggested changes in other measures, including

- recording patient demographics and vital signs

- incorporating clinical lab test results

- generating patient lists by specific conditions

- implementing 5 clinical decision support rules

- providing patients with electronic copies of their health information, and

- giving patients electronic access to their health information within 96 hours after a patient visit

The Academy stood up for some of its most vulnerable members when it told CMS that small practices "do not have the resources for elaborate testing on information systems and electronic data interchange." Those practices would be unable to prove capability to exchange key clinical information among providers of care, submit electronic data to immunization registries or provide electronic submission of reportable lab results to public health agencies, said Epperly.

"We believe there is a real risk for entities to gouge eligible providers to 'assist' them with such testing," he added.

Epperly asked CMS to significantly modify the proposed rule to ensure participation by a majority of physicians. Doing so would move America more quickly toward a patient-centered, coordinated and high-quality health care system, he said.

Sheri Porter
AAFP News Now

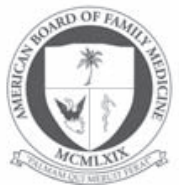

From the American

Board of Family Medicine

Ann Fam Med 2010;8:274-275. doi:10.1370/afm.1126.

\section{FIRST COHORT OF PHYSICIANS IN MC-FP COMPLETE SECOND STAGE IN STRONG NUMBERS}

The American Board of Family Medicine (ABFM) is pleased to announce as of March 1, 2010, almost 8,500 of the Diplomates who certified or recertified in 2003 successfully met the deadline of completing their Stage 1 and Stage 2 requirements for Maintenance of Certification for Family Physicians (MC-FP) and have been granted a 3-year extension of their current certificate, creating a 10-year certificate. The 2003 Diplomates were the first cohort to begin MC-FP and to be eligible 
to extend their 7 -year certificate to a 10 -year certificate. For those Diplomates who certified or recertified in 2006 and who began MC-FP in 2007, close to 8,000 have successfully completed Stage 1 and are currently in Stage 2.

The first 3-year stage of the MC-FP process includes completing either 3 Part II Modules (SAMs), or 2 Part II Modules and 1 Part IV Module (PPM or approved alternate). Stage 2 requirements include 2 Part II Modules (SAMs) and 1 Part IV Module (PPM or approved alternate). These requirements may be completed anytime prior to the deadline. The ABFM Web site will immediately indicate the 3-year certificate extension upon Diplomates' completion of Stage 2 requirements.

The Diplomates who certified or recertified in 2007, and who began MC-FP in 2008, must complete their Stage 1 requirements by December 31, 2010. To date, close to 3,800 of the 2008 cohort have completed 1 or more SAM and are on track to complete their Stage 1 requirements by the end of the year.

Diplomates who certified or recertified in 2008 have until December 31, 2011 to complete Stage 1 requirements.

Diplomates who certified or recertified in 2009 may now begin working on the MC-FP Modules at their convenience. Stage 1 requirements due by December 31,2012 .

In order to help all Diplomates keep track of their progress in MC-FP, the ABFM has updated its Web site to reflect the 7-year or 10-year track chosen by the Diplomate. All Diplomates are encouraged to visit the ABFM Web site (http://www.theabfm.org) and login to the physician's portfolio section. The ABFM Web site now publicly reports MC-FP status as part of Diplomate certification status.

Jane Ireland

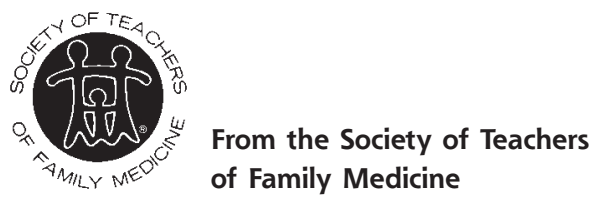

Ann Fam Med 2010;8:275-277. doi:10.1370/afm.1130.

\section{NEW WEB-BASED COURSES FOR IMG RESIDENTS AVAILABLE}

The Society of Teachers of Family Medicine (STFM) has developed a new series of Web-based courses for incoming International Medical Graduate residents. These courses were created to better prepare residents who may be unfamiliar with the role of the family physician in the United States and to familiarize them with the US health care system and residency training programs.

Many residents who have trained outside the US health care system in medical school have good knowledge of how clinical medicine is practiced from a scientific standpoint. However, the US system is often daunting: private insurers, government funders, regulators, patients, and families all have different expectations of physicians. STFM's new Web-based courses are designed to help new residents take the guesswork out of participating in the health care system, working with patients and families in the US culture, and finding a path in the practice of family medicine.

Since many STFM members are often teachers of residents who have no familiarity with the US health care system, we think these new courses will be of interest to most STFM members and their residency colleagues. These courses will allow new IMG residents to be better prepared to begin their clinical trainingby teaching practical skills such as:

- what is Medicaid and how does it work?

- how to drape a patient for privacy

- how to do a SOAP note

The courses to be offered include:

- The US health care system

- Expectations of American patients

- Communication with patients and families

- Operations of a family medicine residency program

- Succeeding in a US family medicine residency program

\section{Background}

An initial needs assessment was led by Deb Simpson and colleagues from STFM, which indicated the areas of need from both program faculty and IMG trainees. This was the basis of curriculum development for the workshop series launched in 2007 for IMG trainees.

The courses included:

- IMG Entering Resident Academy, held in Philadelphia, Pennsylvania, May 18-20, 2007 with 24 attendees

- Applicant Academy, held in Chicago, Illinois, September 16-18, 2007 with 9 attendees

- Entering Resident workshop (2008) (the higher attended of the 2 in 2007) was offered in Philadelphia in May and in Chicago in June

The attendees at these workshops in 2007 and 2008 rated the content and the presenters very high, and STFM received good feedback on the program. However, STFM had hoped to be able to reach a broader audience of residents and programs. After 